\title{
Erken çocuklukta işitme cihazı uygulamaları ve ebeveynler*
}

\section{Hearing aids implementations in early childhood and parents}

\section{Makale Geçmişi \\ Geliş : :10 Ocak 2018 \\ Düzeltme : 06 Mart 2018 \\ Kabul : 09 Mart 2018}

Makale Türü

Derleme Makale

\section{Article History}

Received : 10 January 2018

Revised : 06 March 2018

Accepted :09 March 2018

Article Type

Review Article

\author{
Nurdan Cankuvvet Aykut ${ }^{1}$, Merve Çınar ${ }^{2}$
}

Öz: İșitme kaybına işitme cihazlarıyla müdahaledeki amaç, mümkün olan en erken dönemde ses ve konuşma uyaranına erişimi sağlamaktır. Ancak çocuklarda cihazlandırma, işitme kaybına müdahale için bir başlangıç olarak kabul edilmelidir. İşitme kaybının müdahalesinde kullanılan yardımcı teknolojiler diğer engel türlerinden işitme kaybını ayırmakta, ebeveynlerin müdahale hakkında detaylı bilgilendirmesini zorunlu kılmaktadır. Bu bilgilendirme işitme kaybının doğasını, işitme cihazlarının özelliklerini, kullanım süresini, kullanım özelliklerini ve bakımını kapsamalıdır. İșitme kaybı ve müdahalesine ilişkin yeterli bilgi sağlanmadığında, işitme cihazları düzenli kullanılmamakta veya teknik sorunların çözülmesi gecikmektedir. Doğru bir bilgilendirme ebeveynlerin tüm bu zorlukların üstesinden gelmesini sağlayarak, müdahalenin verimliliğini artıracaktır. Bu bağlamda mevcut derlemede çocuklarda işitme cihazı uygulamalarında ebeveynlerin rolleri ve bu rollerin müdahale sürecine getirdiği açıllmlar betimlenmiştir. Erken çocukluk döneminde işitme cihazı uygulamalarını ve ebeveynlerin rollerini betimlemeyi amaçlayan derlemede, işitme kaybının müdahale sürecinde ebeveynlerin yaşadıkları sorunlara kavramsal olarak değinilmiş, ebeveynlerin yaşadığı bu sorunları en aza indirebilmek adına yapılacak doğru bir bilgilendirme sürecine yönelik farklı önerilere yer verilmiştir. Bu amaç doğrultusunda yapılanan derleme türü bu çalışmada yazarların erken çocukluk dönemi işitme cihazı uygulamalarına ilişkin klinik deneyimi temelinde alanyazın bilgilerinin sentezi, yorumu ve değerlendirilmesi yapılmıştır.

Anahtar Kelimeler: İşitme kaybı, işitme cihazı, ebeveynler, erken çocukluk

Abstract: The aim of intervention to hearing loss with the hearing aids is to provide opportunity to access sound. However, assistive hearing technology used in intervention to hearing loss, not only separates the other disabilities from hearing loss, but also necessitates parents get informed about intervention process. Informing process should include the nature of hearing loss, the hearing aids properties, the duration of use, maintenance and care. When adequate knowledge is not provided, hearing aids are not used properly and resolution of technical difficulties is delayed. Informing parents accurately will increase the efficiency of the intervention by ensuring that parents are able to overcome all these difficulties. In this context, the present review describes, roles of parents and effects of these roles to the process of intervention with hearing aids. This review addresses problems that parents come accross in the intervention process conceptually, and includes suggestions towards informing process to decrease the amount of problems which parents go through. In accordance with this purpose, synthesis, interpretation and evaluation of the literature on the issue of hearing aids in the early childhood, which is clinically experinced by the authors, has been integrated in this review article.

Keywords: Hearing loss, hearing aids, parents, early childhood

\footnotetext{
*5.Uluslararası Okul Öncesi Eğitim Kongresinde “Sözlü Bildiri” olarak sunulmuştur.

${ }^{1}$ Anadolu Üniversitesi, Sağlık Bilimleri Fakültesi, Odyoloji Bölümü, ncankuvvet@anadolu.edu.tr

${ }^{2}$ Anadolu Üniversitesi, Sağlık Bilimleri Fakültesi, Odyoloji Bölümü, m_cinar@anadolu.edu.tr
} 


\section{SUMMARY}

\section{Introduction}

By means of sense of hearing, we, as human beings, can communicate with others verbally. If the sense of hearing is damaged or absent, individuals with the loss are denied the opportunity to sample an important feature of their environment, the sounds emitted by nature and by humans themselves. Consequently, if appropriate early intervention does not occur within the first months, hearing loss can be devastating to the development of spoken communication, to the development of sophisticated language use, and to many aspects of social and educational development, if environmental and educational compensation does not occur (Martin and Clark, 2009; Marschark, 2007; Marschark, Green, Hindmarsh and Walker, 2000; Rieffe, Terwogt and Smith, 2003; Tüfekçioğlu, 2010; Yost, 2006).

Because of hearing loss adverse effects on development, early intervention is vital for child, parents and society (Cankuvvet, 2017). Newborn hearing screening and the early detection/intervention programs which is widespread now in global scale, have paved the way forward for improving the quality of life for children with a hearing loss (Health of Ministy of Turkey, 2017; Joint Committee on Infant Hearing, 2007; Moeller, 2000; Vohr, 2003; Yoshinaga-Itano, 2003). The implementation of universal newborn hearing screening has led to earlier diagnosis and amplification fitting which are crucial for spoken language development for children with hearing loss (Genç ve Barmak, 2012; Moeller, 2000; Munoz, Blaiser and Barwick, 2013; Tomblin et al., 2015; Tomblin, Oleson, Ambrose, Walker and Moeller, 2014; Turan, Taşkıran Küçüköncü, Cankuvvet ve Yolal, 2012; Vohr, 2003; Yoshinaga-Itano, 2003). Even when hearing aids are fitted at an early age, many parents encounter difficulties in achieving effective daily management that supports consistent hearing aid use which is crucial for success of intervention (Calderon, 2000; DesJardin, 2006; Jackson, Traub and Turnbull, 2008; Munoz, Preston and Hicken, 2014). At this point parental education is critical to assist parents to learn new information and skills to address their child's needs and for problem-solving challenges that arise. Parental education must include nature of hearing loss, effects of loss on auditory system, roles of hearing aids in intervention process and responsibilities of parents during this process (Cankuvvet, 2015, Munoz et al., 2014). Experts, especially audiologists, have an important role in partnering with parents to inform them as they learn to effectively manage their child's hearing aids day-to-day, providing parent education and support for parents' emotional needs related to their child's hearing loss (American Speech and Hearing Association, 2008; Munoz et al., 2015; Munoz et al., 2016;).

\section{Acquiring the Hearing Aids}

Hearing aids are sold in different models by different companies with variety of price. Parents desire the best conditions for their children, so they want to buy best quality of hearing aids. Hearing aids quality not depends on price but hearing loss type and grade. So parents need to be informed about suitable hearing aids for their child's hearing loss. Even with right consulting, pecuniary obligation is still a 
problem for most parents (Duncan, 2009; Hintermair, 2006; Jackson et al., 2008; Li, Bain and Steinberg, 2004; Luterman, 2004; Zaidman-Zait and Most, 2005).

\section{Hearing Aid Use}

For children fitted with hearing aids, a foundational aspect of their auditory experience is dependent on the ongoing management of their amplication including consistent use of well- functioning hearing aids (Cole and Flexer, 2007; Estabrooks, 2006; Munoz et al., 2015). Recent research, however, has shown that hearing aid use is highly variable for young children (Munoz et al., 2013; 2016). This inconsistent use of hearing aids is not enough for auditory experience which is needed for language development. Regardless of the degree of hearing loss, children with hearing loss are at risk for developmental consequences as a result of their hearing so audiologists must inform parents on the importance of the proper use of hearing aids, especially; using them all day long.

\section{Maintenance of Hearing Aids}

Parents have reported encountering a variety of challenges with hearing aid management and use, including problems with hearing aid care and maintenance which includes battery issues or ear mold. Because hearing aids may malfunction and require maintenance, daily hearing aid controls are important. The author's clinical experience and research findings consistently revealed that parents have serious problems on maintenance of hearing aids and need outgoing consulting (Anagnostou, Graham and Crocker, 2007; Munoz et al., 2015; Kurtzer-White and Luterman, 2003; Munoz et al., 2015; Sjoblad, Harrison, Roush and McWilliam, 2001; Walker et al., 2013). The main reason behind maintenance hesitations is pecuniary concerns of parents because they worry about endamaging them. If they endamaged hearing aid, it would cause out of warranty situations and more importantly block child's auditory experience. Parents reported that if their needs for hearing aid education and support were met; it would made feel them competent about hearing aids (Munoz et al., 2016).

\section{Conclusions and Suggestions}

Nowadays the answer of "What is main context of development?" question is parents. Therefore the intervention process must focus on parents and their needs (Cavkaytar, Ceyhan, Adigüzel, Uysal and Garan, 2014; Cavkaytar, 2010). Hearing aid managements in early childhood should begin with proper informing of parents about hearing aid use, maintenance of hearing aids and trouble-shooting of technical problems which lead to active involvement of parents in intervention process. Experts are more likely to meet the needs of families if they take care to provide access to thorough and complete education and ongoing support that is tailored to address the unique needs of individual families.

This review which focus on hearing aid implementation in early childhood reveals important hiatus in national literature. Unfortunately there is no research conducted on parents' problems or related solutions in national literature. On the other hand, international literature and the author's clinical experience correspond with the others' on the issue of hearing aid implementation in early childhood. 
Future national studies conducting on this matter may support evidence based clinical practice and shape related politics. 


\section{GíRIȘ}

İşitme duyusu çevremizle iletişim kurmamızı sağlayarak, sözel dil gelişimini temellendirmektedir. İşitme duyusunun hassasiyetinin azalması veya ortadan kalkması olarak tanımlayabileceğimiz işitme kaybı (Martin ve Clark, 2009; Yost, 2006) nedeniyle sözel dil gelişiminde oluşan sorunlar; çocuğun bilişsel, sosyal ve duygusal gelişimine de yansımaktadır. Gelişimdeki bu gecikmeler, çocuk okul yaşına geldiğinde akademik başarısının düşük olmasıyla sonuçlanmaktadır (Marschark, 2007; Marschark, Green, Hindmarsh ve Walker, 2000; Rieffe, Terwogt ve Smith, 2003; Tüfekçioğlu, 2010). Tüm bunlar, işitme kayıplı bireyin özerk bir yaşam sürme imkânını kısıtlamaktadır (Marschark, 2007).

Çocukluktan yetişkinliğe gelişimi her anlamda olumsuz etkileyen işitme kaybının erken tanısı ve müdahalesi çocuk, çocuğun ebeveynleri ve içinde yaşadığ taşımaktadır (Cankuvvet, 2017). Bu bağlamda dünyada işitme kaybının erken tanısını ve müdahalesini hedefleyen Yenidoğan İşitme Tarama Programı (YİTP) giderek yaygınlaşmaktadır (Joint Committee on Infant Hearing, 2007; Moeller, 2000; Vohr, 2003; Yoshinaga-Itano, 2003). Ülkemizde 2004 yılında başlayan ve 2018 yılı itibariyle tüm illerde devam eden Ulusal Yenidoğan İşitme Tarama Programı (UYITP) kapsamında yenidoğanlar hastaneden çıkmadan önce işitme kaybı açısından taranmaktadır (Bolat ve Genç, 2012; Cankuvvet, 2017; Genç, Ertürk ve Belgin, 2005; Kayıran, Genç, Erdil ve Gürakan, 2009; Övet, Işık Balc1, Canural ve Çövüt, 2010; Sağlık Bakanlığı 2017). Konuyla ilgili yürütülen araştırmalarının sonuçları değerlendirildiğinde, programın işitme kaybının tanısı ve müdahalesi açısından verimliliği ortaya çıkmaktadır. Ulusal Yenidoğan İşitme Tarama Programı sayesinde pek çok bebeğe henüz daha yenidoğan döneminde işitme kaybı tanısı konulmakta ve bu da erken müdahalenin önünü açmaktadır. Örneğin yapılan bir çalışmada, 2004-2009 yılları arasındaki tarama sonuçları değerlendirildiğinde, işitme kaybı açısından taranan 8052 yenidoğanın \%0.06'sında çift taraflı, \%0.05'inde tek taraflı sensörinöral işitme kaybı olduğu saptanmış ve bu çocuklar müdahale programına vakit kaybetmeden dahil edilmiştir (Kayıran vd., 2009). Diğer bir çalışmada ise, 2010-2012 yılları arasında 5605 bebeğin tarama sonuçları değerlendirilmiştir. Bu bebeklerin 88'inde farklı derecelerde işitme kaybı saptanırken, ortalama tanı yaş1 7.4 ay, müdahale yaşı ise 9.6 ay olarak bulunmuştur (Türkmen vd., 2013). Bolat (2007), 4497 bebekle yürüttüğü çalışmasında, bu bebeklerin 7'sinde (\%0.15) işitme kayb1 olduğunu saptamıştır. Bu 7 bebekten 4'ü vakit kaybetmeden cihazlandırılmış ve ebeveynleriyle birlikte aile eğitimi programlarına dahil olmuştur. Bu bebeklerden 2'sinde tek taraflı işitme kaybı olduğundan işitme cihazı hemen önerilmemiş, bebekler odyolojik takip programına 
alınmıştır. Çalışmanın sürdüğü zaman aralığında işitme cihazı önerilmiş bir bebeğin henüz işitme cihazlarını edinemediği görülmüştür. Çalışmada ortalama işitme cihazı edinim zamanının 7 ay 25 gün olduğu belirtilmiştir. Araştırma Aydın il merkezindeki yenidoğanlarda sensörinöral işitme kaybının görülme sıklığının 1.5/1000 olduğunu belirtmektedir. Bu sonuçlar yenidoğan döneminde işitme kaybının önemli bir sorun olduğunu gösterirken, Ulusal Yenidoğan İşitme Tarama Programı'nın verimliliğini de ortaya koymaktadır (Bolat, 2007). Diğer bir ifadeyle, tarama programı sayesinde işitme kaybı erken dönemde saptanmakta, işitme cihazlarıyla müdahale başlamaktadır (Bolat, 2007; Kayıran vd, 2009; Moeller, 2000; Munoz, Blaiser ve Barwick, 2013; Renda, Özer ve Renda, 2012; Türkmen vd., 2013; Vohr, 2003; Yazgan, Keleş, Gebeşçi, Demirdöven ve Uzun, 2012; Yoshinaga-Itano, 2003).

İşitme kaybında cihazlandırma ve işitme cihazlarını düzenli kullanma dil ve konuşma gelişimi için büyük bir önem taşımaktadır (Tomblin vd., 2015; Tomblin, Oleson, Ambrose, Walker ve Moeller, 2014; Turan, Taşkıran Küçüköncü, Cankuvvet ve Yolal, 2012). Ebeveynlerin cihazı edinmesi, çocuklarına işitme cihazlarını tüm gün kullandırmaları ve cihazın bakımını sağlamaları müdahalenin başarısını belirlemektedir (Calderon, 2000; DesJardin, 2006; Jackson, Traub ve Turnbull, 2008; Munoz, Preston ve Hicken, 2014). Ebeveynler bunları yapamadığında, işitme kaybı ne kadar erken tanılanırsa tanılansın ne yazık ki arzulanan sonuçlara ulaşmak mümkün olmamaktadır.

Çocuğu işitme kayıplı ebeveynlerle yürütülen araştırmalar, çoğunun (\%95) işitmesinin normal olduğunu göstermektedir. Bunun anlamı, ebeveynlerin işitme kaybına ilişkin deneyim ve bilgilerinin olmadığıdır (Mitchell ve Karchmer, 2004). Dolayısıyla işitme kaybına müdahale süreci, ebeveynlerin bilgilendirilmesini gerektirmektedir (Cankuvvet, 2015). Bu bilgilendirme işitme kaybının doğasını, kaybın işitme sistemi üzerindeki etkilerini, işitme cihazlarının işlevlerini ve ebeveynlerin müdahale sürecindeki sorumluluklarını içermelidir (Cankuvvet, 2015, Munoz vd., 2014). Bilgilendirme sürecinde alan uzmanlar1, ebeveynlerin duygusal ihtiyaçlarını desteklemede ve gereken eğitimi sağlamada kilit bir noktada yer almaktadır (American Speech and Hearing Association, 2008; Munoz vd., 2015; Munoz vd., 2016;). Kapsamlı bir bilgilendirme desteği, ebeveynlerin sürece aktif katılımlarını sağlayarak müdahalenin niteliğini belirleyecektir (Munoz vd., 2016). Müdahale niteliğini belirleyen ilk öğe, işitme cihazlarının en kısa sürede edinilmesidir. 


\section{İşitme Cihazlarını Edinme}

Müdahalenin başlayabilmesi için öncelikle çocuğun işitme cihazlarını kullanmaya başlaması gerekmektedir. $\mathrm{Bu}$ süreçte ebeveynlerin öncelikli rolü vakit kaybetmeden işitme cihazlarını edinmektir. İşitme cihazları piyasada farklı firmalar tarafından farklı modellerde satışa sunulmaktadır. Çocukları için en iyi şartları hazırlamak isteyen ebeveynler doğal olarak en iyi işitme cihazını almak istemektedir. İşitme cihazlarının niteliğini sadece fiyatları değil işitme kaybının tipi ve derecesiyle olan uyumları belirlemektedir. Dolayısıyla işitme cihazlarını edinme sürecinde ebeveynlerin ihtiyacı, doğru bir bilgilendirme ve yönlendirmedir. Ancak bu yönlendirmeler doğru yapılsa dahi işitme cihazlarının maddi yükümlülükleri de ebeveynleri çoğu zaman zorlamaktadır. Ülkemizde Sosyal Güvenlik Kurumu (SGK), Sağlık Uygulama Tebliği (SUT) dahilinde işitme cihazları için ödenen katkı miktarını belirlemiştir (Resmi Gazete, 2017). SGK'nın belirlediği ödeme miktarı işitme cihazı kullanıcısının yaşına ve sağlık güvencesine göre değişkenlik göstermektedir. Erken çocukluk döneminde kullanılan programlanabilir dijital işitme cihazları için 2018 yılı itibariyle SGK'nın karşıladığı ödeme tutarları Tablo 1'de sunulmuştur.

Tablo 1. Programlanabilir dijital işitme cihazları için ödeme tutarları

\begin{tabular}{lcc}
\hline & \multicolumn{2}{c}{ Ödeme Tutarı (TL) } \\
\hline Yaş Aralığı & Emekli\&Yakını & Çalışan\&Yakını \\
$0-4$ yaş & $1275.00 \mathrm{TL}$ & $1080.00 \mathrm{TL}$ \\
$5-12$ yaş & $1080.00 \mathrm{TL}$ & $960.00 \mathrm{TL}$ \\
$13-17$ yaş & $1012.50 \mathrm{TL}$ & $900.00 \mathrm{TL}$ \\
18 yaş ve üzeri & $675.00 \mathrm{TL}$ & $600.00 \mathrm{TL}$ \\
\hline
\end{tabular}

Tablo 1 incelendiğinde, işitme cihazları için SGK'nın karşıladığı ödeme tutarlarının sosyal devlet kavramıyla uyumlu ancak yetersiz olduğu göze çarpmaktadır. Piyasadaki firmalardan biriyle yapılan kişisel görüşmeden elde edilen bilgi oldukça çarpıcıdır. Kulak arkası standart (minimal özellikli) bir modelin fiyatının ortalama $2.500 \mathrm{TL}$ olduğu belirtilmiştir (Firma Yetkilisi, kişisel görüşme, Kasım 2017). Bu tabloya göre 6 aylık bir bebeği olan ve çalışan bir ebeveynin, çift taraflı kullanılan işitme cihazlarını edinmek için, kendi maddi imkanlarını kullanarak ödemesi gereken miktarın ortalama 3.840 TL olduğu görülmektedir. Daha önce de belirtildiği gibi alınabilecek cihaz, standart özelliklere sahiptir. Cihazın özellikleri detaylandıkça fiyatı da belirgin biçimde artmaktadır. Tüm bunlar işitme cihazlarını edinme sürecinin ebeveynleri özellikle maddi açıdan oldukça zorlayabileceğini göstermektedir. $\mathrm{Bu}$ durum sadece ülkemiz için geçerli değildir. Uluslararası araştırmalar da, cihazın maddi 
gereksinimlerinin ebeveynleri zorladığını göstermektedir (Duncan, 2009; Hintermair, 2006; Jackson vd., 2008; Li, Bain ve Steinberg, 2004; Luterman, 2004; Zaidman-Zait ve Most, 2005).

\section{İşitme Cihazlarının Düzenli Kullanımı}

İşitme kaybına müdahalede cihazları edinme sürecini takip eden aşama cihazların düzenli kullanımıdır. Müdahalenin başarıya ulaşabilmesi için çocukların öncelikle cihazlarını düzenli kullanmas1 gerekmektedir. Bu noktada devreye yine bilgilendirme girmektedir. Ebeveynlere yeterli bilgi sağlanmadığında, işitmeye yardımcı teknolojiler, gözlük gibi engeli ortadan kaldıran bir araç olarak görülebilmektedir. Cankuvvet'in (2015) belirttiği gibi, görme duyusunda sorun olan bir çocuk gözlük taktığında görmeyi öğrenmesi gerekmemektedir. Aynı mantık işitme cihazlarına yansıtıldığında; ebeveynin beklentisi çocuğun işitme cihazlarıyla tüm sesleri duymaya başlayacağı ve kısa sürede sözel dil gelişiminin kendiliğinden gerçekleşeceği yönünde olacaktır. Gözlüğün aksine işitme cihazları işitme sisteminin işlevlerini tam anlamıyla yerine getirememektedir. Çocuğun sesleri duyması ve anlamlandırması zaman almakta, ancak yoğun bir işitsel deneyim sonrasında olmaktadır (Cole ve Flexer, 2007; Estabrooks, 2006). Bu yoğun işitsel deneyimse işitme cihazlarının düzenli kullanımıyla mümkün olmaktadır (Munoz vd., 2015).

İşitme cihazlarının kullanımını değerlendiren araştırmaların bulguları, ebeveynlerin kullanım sürelerine ilişkin yeterli bilgi sahibi olmadığını düşündürmektedir. Örneğin bir çalışmada ebeveynlerin \%84'ü, çocuklarının günde ortalama 2.6 saat işitme cihazı taktığını belirtmektedir (Munoz vd., 2016). 0-4 yaş aralığında 5000 çocukla yürütülen diğer bir çalışmada işitme cihazı kullanım süresinin 4-5 saat olduğu ortaya koyulmuştur (Jones, 2013). Benzer şekilde 29 çocukla yapılan başka bir çalışmada 0-5 yaş aralığında işitme cihazı kullanım süresi 4.6 saat olarak belirtilmiştir (Munoz vd., 2016). Tüm bu araştırmaların gösterdiği en çarpıcı taraf, çocukların işitme cihazlarını düzenli kullanmadığıdır. Oysa ki işitme kaybında müdahalenin başarıya ulaşabilmesi için çocuğun uyanık olduğu tüm zamanlar işitme cihazlarını kullanması ve nitelikli işitsel uyarana maruz kalması gerekmektedir. Bu olmadığında işitme cihazlarıyla beklenen dil ve konuşma gelişimi ne yazık ki sağlanamayacaktır. Bu bağlamda ebeveynleri işitme cihazlarının düzenli kullanımı hakkında bilgilendirmek alan uzmanlarının önceliklerinden biri olmalıdır. Yazarların klinik deneyimi de uluslararası araştırmaların bulgularıyla örtüşmekle birlikte, erken çocukluk döneminde işitme cihazı kullanım sürelerini değerlendiren ulusal bir araştırmaya rastlanmamaktadır. $\mathrm{Bu}$ bağlamda mevcut derleme, müdahalenin başarısını belirleyen işitme cihazı kullanım sürelerine ilişkin yürütülecek ulusal araştırmalara olan ihtiyacı göstermesi açısından da anlamlıdır. 


\section{İşitme Cihazlarının Bakımı}

İşitme cihazlarına ilişkin diğer önemli bir nokta düzgün çalışmaları için düzenli bakımlarının yapılmasıdır. Bakımdan kasıt cihazın çalışabilmesi için gerekli şartların her durumda sağlanmasıdır. İşitme cihazları teknolojik aletler olduğundan en temelde çalışmak için enerjiye ihtiyaç duymaktadır. Bu enerji de pillerle sağlanmaktadır. Cihazın pili olmadığında çocuğun kulağına hiç ses gitmeyecektir. Diğer bir ifadeyle çocuk cihazlarını tüm gün kullansa dahi sesleri duymayacaktır. Düzenli kullanımında diğer önemli bir nokta kulak kalıplarının bakımıdır. Cihazın kulakla olan bağlantısı kalıp-hortum gibi aparatlarla kurulmaktadır. Kalıp kulak kiriyle tıkandığında veya hortum yırtıldığında çocuğun kulağına ya hiç ses gitmeyecek ya da giden sesin kalitesinde bozulma olacaktır. Eğer ebeveyn bu konular hakkında doğru bilgilendirilirse, cihazın pili, kalıp-hortumunu değiştirerek, basit teknik sorunları giderebilecektir. Cihazların kullanımında dikkat edilmesi gereken diğer bir nokta, pil kapağı açık bırakılarak cihazın kapatılmasıdır. Bu yapılmadığında cihaz çalışmaya devam edecek ve pil ömrü oldukça kısalacaktır. Bu gibi sorunlar göz önüne alındığında, ebeveynlerin işitme cihazlarının bakımı hakkında da bilgilendirilmesi gerekmektedir. İşitme cihazlarının bakımına ilişkin ulusal alanyazın değerlendirildiğinde, kullanım sürelerinde olduğu gibi, ebeveynlerin sürece ilişkin deneyimlerini değerlendiren bir araştırmanın olmaması oldukça çarpıcıdır. Oysa ki uluslararası araştırmalar ve yazarların klinik deneyimleri ebeveynlerin cihazın bakımıyla ilgili sorunlar yaşadıklarını açıkça göstermektedir (Anagnostou, Graham ve Crocker, 2007; Munoz vd., 2015; Kurtzer-White ve Luterman, 2003; Walker vd., 2013). Ebeveynler işitme cihazlarının bakımına ilişkin bilgileri anlamakta zorlanmakta ve bu sebeple de işitme cihazlarını düzenli kullanamadıklarını belirtmektedir (Anagnostou vd., 2007; Kurtzer-White ve Luterman, 2003; Munoz vd., 2015; Sjoblad, Harrison, Roush ve McWilliam, 2001; Walker vd., 2013).

Ebeveynlerin işitme cihazlarının bakımını sağlamakta zorlanmalarının diğer bir nedeni ise maddi kaygılardır. Ebeveynler çoğu zaman işitme cihazlarını bozacakları endişesiyle basit teknik sorunlara müdahale etmekten çekinmektedir. Çünkü yanlış bir müdahale hem cihazın garanti kapsamından çıkmasına neden olacak hem de tamir sürecinde çocuk işitme cihazsız kalacaktır. Tüm bu kaygılar, ebeveynlerin işitme cihazıyla doğru bir ilişki kurmasını engellemektedir (Munoz vd., 2016; Spahn, Richter, Burger, Löhle ve Wirsching, 2003). Bu sorunlarla ilişkili olarak yürütülmüş bir çalışmada, çocuğu işitme cihazı kullanmaya başlamış dört ebeveynle video-tele konferans yoluyla iletişim kurulmuş, cihazlarla ilgili sıkıntıları sorulmuş ve danışmanlık yapılarak sorunlar giderilmiştir. Çalışmaya katılan ebeveynlerin altı ay sonunda işitme cihazlarında bir sorun oluştuğunda müdahale etme sıklıkları artmış ve teknik 
servislere başvurma sıklıkları azalmıştır (Munoz vd., 2016). Diğer bir ifadeyle bilgilendirme yoluyla kendilerini işitme cihazlarına ilişkin konularda daha yetkin hisseden ebeveynlerin müdahale sürecine katılımları artmıştır.

\section{SONUÇ VE ÖNERÍLER}

Günümüzde erken çocuklukta "Gelişimin ana bağlamı nedir?” sorusunun cevabı, ebeveynler olarak verilmektedir. Artık erken çocuklukta müdahale çocuk merkezli uygulamalardan aile merkezli uygulamalara evrilmiştir. Bu uygulamaların amacı, mümkün olan en erken dönemde gelişimsel geriliklerin önlenebilmesi için çocuğun ve ebeveynin ihtiyacı olan desteğin sağlanmasıdır (Cavkaytar, Ceyhan, Adıgüzel, Uysal ve Garan, 2014; Cavkaytar, 2010).

$\mathrm{Bu}$ bağlamda erken çocukluk döneminde işitme cihazı uygulamalarını düşündügümüzde, ebeveynlerin rollerinin belirlenmesi ve roller temelinde ihtiyaçları olan desteğin sağlanması, müdahalenin başarısında vazgeçilmez bir öneme sahiptir. Erken çocukluk dönemi işitme cihazı uygulamalarında ebeveynlerin öncelikli ihtiyacı doğru bir bilgilendirmedir. İşitme cihazlarının edinilmesiyle başlayan müdahale süreci; cihazların düzenli kullanımı, bakımı ve basit teknik sorunların giderilmesi gibi konularda ebeveynlerin bilgilendirilmesini gerektirmektedir (Calderon, 2000; Duncan, 2009; Hintermair, 2006; Munoz vd., 2014; Munoz vd., 2015; Munoz vd., 2016; Sjoblad vd., 2001; Walker vd., 2013). Bilgilendirme sonrası ebeveynler çocuklarının işitme cihazlarıyla ilgili günlük ihtiyaçlarına cevap verebilmeli, bir sorun olduğunda çözme yetkinliğine sahip olmalıdır (Jones, 2013; Munoz vd., 2016; Zaidman-Zait ve Most, 2005). Aktarılan alanyazın da bilgilendirmenin önemini açıkça ortaya koyarken, kendini yetkin hisseden ebeveynlerin müdahale sürecine daha aktif katıldığını göstermektedir (Calderon, 2000; Cankuvvet, 2015; Duncan, 2009; Hintermair, 2006; Munoz vd., 2014; Munoz vd., 2016; Zaidman-Zait ve Most, 2005).

İşitme kaybında müdahale bir zincir gibi düşünülmelidir. Sürecin herhangi bir kısmında meydana gelen kopukluk, tüm süreci etkilemektedir. Bu noktada bilgilendirme, zincirin halkalarını bağlayan ana öğe olarak görülmelidir (Cankuvvet, 2015). Ebeveynler ne kadar nitelikli bilgilendirilirse müdahale o kadar başarılı olacaktır. Dolayısıyla alan uzmanları ebeveynlerle bir ortaklık ilişkisi kurup, ebeveynlerin problem çözme becerilerini artırmalıdır. Ebeveyn ve uzman arasında ortaklığa dayalı bir ilişki kurulmadığında müdahalenin önemli bir ayağı eksik kalacaktır. Bu eksiklik çocuğun gelişimine yansıyarak, özerk bir yetişkin olmasının önünde bir engel oluşturacaktır. 
Erken çocukluk döneminde işitme cihazı uygulamalarını değerlendiren bu derleme, ulusal alanyazın açısından önemli bir eksikliği göstermektedir. Uluslararası araştırmaların ortaya koyduğu bulgular yazarların klinik deneyimiyle birebir uyuşmaktadır. Ancak ulusal alanyazında ebeveynlerin işitme cihazını edinirken, kullanırken ve bakımlarını sağlarken karşılaştıkları sorunlar ve buna getirilen çözümlere ilişkin bir araştırmaya rastlanmamaktadır. İşitme kaybının müdahalesi için bu denli önemli bir konu olan işitme cihazı uygulamaları ve ebeveynlerin bu uygulamalara ilişkin deneyimlerini değerlendiren araştırmalar, işitme kaybı alanında verilen hizmetlerin kalitesini kuşkusuz ki arttıracaktır. Aile merkezli uygulamaların amacıyla uyumlu bir biçimde, işitme cihazı uygulamalarındaki sorunlar temelinde ebeveynin ihtiyacı olan desteğin sağlanması, gelişimsel geriliklerin önlenebilmesi adına atılması gereken önemli adımlardan biri olacaktır (Cavkaytar, Ceyhan, Adıgüzel, Uysal ve Garan, 2014; Cavkaytar, 2010). Erken çocukluk döneminde işitme cihazı uygulamalarında çözüm odaklı bir sürecin kanıta dayalı uygulamalarla desteklenmesi, ülkemizde erken müdahale uygulamalarının verimliliğini artırmakla kalmayıp, ulusal alanyazını da zenginleştirebilir. Konuyla ilgili desenlenecek araştırmalar klinik pratiği kanıta dayalı uygulamalarla destekleyip, ilgili politikalara da yön verebilir.

\section{KAYNAKÇA}

Anagnostou, F., Graham, J. \& Crocker, S. (2007). A preliminary study looking at parental emotions following cochlear implantation. Cochlear Implant International, 8(2), 68-86.

American Speech and Hearing Association. (2011, 2014). 13 Kasim 2017 tarihinde http://www.asha.org/ adresinden erişildi.

Bolat, H. \& Genç, A. (2012). Türkiye ulusal yenidoğan işitme taraması programı: Tarihçesi ve prensipleri, Türkiye Klinikleri J E.N.T.-Special Topics, 5(2),11-24.

Bolat, H. (2007). Aydın ilinde 2006 yılında doğan bebeklerde işitme kaybı sıklı̆̆l ve ilişkili risk faktörleri, Yayımlanmamış Doktora Tezi, Gazi Üniversitesi, Ankara.

Calderon, R. (2000). Parental involvement in deaf children's education programs as a predictor of child's language, early reading, and social-emotional development. Journal of Deaf Studies and Deaf Education, 5, 140-155.

Cankuvvet, N. (2017). İşitme yetersizliğinde tarama, tanı, değerlendirme. İçinde H. Gürgür ve P. Şafak (Ed.) İşitme ve Görme Yetersizliği. (s.99-126) Ankara: Pegem Akademi.

Cankuvvet, N. (2015). Çocuğu koklear implant adayı ebeveynlerin gereksinimlerine dayalı bilgilendirme programı geliştirilmesi, Yayımlanmamış Doktora Tezi, Anadolu Üniversitesi, Eskişehir.

Caykaytar, A., Ceyhan, E., Adıü̈zel, O.C. \& Garan, Ö. (2014). Aile bilgi ve destek programı (E-ABDEP):Zihinsel yetersizliğe sahip çocuğu olan ebeveynlerin eğitiminde çevrimiçi bilgilendirme ve hizmetlerinin etkililiği, TÜBİTAK, Proje No: 1005E102.

Cavkaytar, A. (2010). Özel ĕgitimde aile eğitimi ve rehberliği. Ankara: Maya Akademi. 
Cole, E. B. \& Flexer, C. (2007). Children with hearing loss: Developing listening and talking, birth to six. San Diego, Oxford, Brisbane: Plural Publishing.

DesJardin, J. L. (2006). Family empowerment: Supporting language development in young children who are deaf or hard of hearing. Volta Review, 106(3), 275-298.

Duncan, J. (2009). Parental readiness for cochlear implant decision making. Cochlear Implants International, 10(1), 3842.

Estabrooks, W. (2006). Auditory-verbal therapy: Theory and practice. Washington DC, AG Bell. Association for the Deaf.

Genç, G. A., Ertürk, B. B. \& Belgin, E. (2005). Yenidoğan işitme taraması: Başlangıçtan günümüze. Çocuk Sağlığı ve Hastalıkları Dergisi, 2(48),109-118.

Genç, G. A. \& Barmak, E. (2012). Yenidoğan işitme taramasının konjenital işitme kayıplı bebeğin gelişimine etkisi. Türkiye Klinikleri, 32(5):1284-94.

Hintermair, M. (2006). Parental resources, parental stress, and socioemotional development of deaf and hard of hearing children. Journal of Deaf Studies and Deaf Education, 11(4). 178-209.

Jackson, C. W., Traub, R. J. \& Turnbull, A. P. (2008). Parents' experiences with childhood deafness: Implications for family-centered services. Communication Disorders Quarterly, 29(2), 82-98.

Joint Committee on Infant Hearing [JCIH] (2007). Year 2000 position statement: Principles and guidelines for early detection and intervention programs. Pediatrics, 120(4), 898921.

Jones, C. (2013, December, 9). What do we know about the fitting and daily life usage of hearing instruments in pediatrics? Session presented at the 6th International Pediatric Audiology Conference: A Sound Foundation through Early Amplification; Chicago, IL.

Kayıran, S. M., Genç, E., Erdil, A. \& Gürakan, B. A. (2009). Amerikan Hastanesi yenidoğan işitme taraması sonuçları, Türk Pediatri Arşivi Dergisi, 44:135-7.

Kurtzer-White, E. \&Luterman, D. (2003). Families and children with hearing loss: Grief and coping. Mental Retardation and Developmental Disabilities, 9, 232-235.

Li, Y., Bain, L. \& Steinberg, A. G. (2004). Parental decision-making in considering cochlear implant technology for a deaf child. International Journal of Pediatric Otorhinolaryngology, 68(8), 1027-1038.

Luterman, D. (2004). Counselling families of children with hearing loss and special needs. The Volta Review, 104(4), 215-220.

Marschark, M. (2007). Raising and educating a deaf child. A comprehensive guide to the choices, controversies and decisions faced by parents and educators (4.bs.). New York, NY: Oxford University Press.

Marschark, M., Green, V., Hindmarsh, G. \& Walker, S. (2000). Understanding theory of mind in children who are deaf. Journal of Child Psychology \& Psychiatry \& Allied Disciplines, 41(8), 1067-1074.

Martin, F. H. \& Clark, J. G. (2009). An introduction to audiology (10.bs.). Boston, MA: Allyn \& Bacon. 
Mitchell, R. E. \& Karchmer, M. A. (2004). Chasing the mythical ten percent: Parental hearing status of Deaf and Hard of Hearing Students in the United States. Sign Language Studies, 4 (2), 138-163.

Moeller, M. (2000). Early intervention and language development in children who are deaf and hard of hearing. Pediatrics, 106(3), E43.

Munoz, K., Blaiser, K. \& Barwick, K. (2013). Parent hearing aid experiences in the United States. Journal of the American Academy of Audiology, 24, 5-16.

Munoz, K., Olson, W. A., Twohig, M. P., Preston, E., Blaiser, K. \&White, K. R. (2015). Pediatric hearing aid use: Parent reported challenges. Ear Hear, 36, 279-287.

Munoz, K., Preston, E. \& Hicken, S. (2014). Pediatric hearing aid use: How can audiologists support parents to increase consistency? Journal of the American Academy of Audiology, 25, 380-387.

Munoz, K., Rusk, S., Nelson, L., Preston, E., White, K.R., Barrett, T.S. \& Twohig, M.P. (2016). Pediatric hearing aid management: Parent-reported needs for Learning Support, Ear Hear 37(6), 703-709.

Övet, G., Işık Balc1, Y., Canural, R. \& Çövüt, İ. (2010). Yenidoğan işitme tarama sonuçlarımız, Adnan Menderes Üniversitesi Tıp Fakültesi Dergisi, 11(1):27-29.

Renda, L., Özer, E. \& Renda, R. (2012). Ankara Polatlı Devlet Hastanesi yenidoğan işitme taraması programı:6 y1llı sonuçlar, Pamukkale Tıp Dergisi; 5(3):123-127.

Resmi Gazete (2017). Sosyal Güvenlik Kurumu Sağlık Uygulama Tebliğinde Değişiklik Yapılmasına Dair Tebliğ. $13 \quad$ Kasım 2017 tarihinde http://www.resmigazete.gov.tr/eskiler/2017/06/20170608-8.pdf adresinden erişildi.

Rieffe, C., Terwogt, M. M. \& Smith, C. (2003). Deaf children on the causes of emotions. Educational Psychology, 23(2), 159-169.

Sağlık Bakanlığı (2017). 13 Kasım 2017 tarihinde http://isitmetarama.saglik.gov.tr/Login.aspx adresinden erişildi.

Sjoblad, S., Harrison, M., Roush, J. \& McWilliam, R. (2001). Parents' reactions and recommendations after diagnosis and hearing aid fitting. American Journal of Audiology, 10, 24-31.

Spahn, C., Richter, B., Burger, T., Löhle, E. \& Wirsching, M. (2003). A comparison between parents of children with cochlear implants and parents of children with hearing aids regarding parental distress and treatment expectations. International Journal of Pediatric Otorhinolaryngology, 6(4). 69-98.

Tomblin J. B., Harrison M., Ambrose, S. E., Walker E. A., Oleson J. J. \& Moeller M. P. (2015). Language outcomes in young children with mild to severe hearing loss. Ear Hear, 36.

Tomblin J. B., Oleson J. J., Ambrose S. E., Walker, E. \& Moeller M. P. (2014). The influence of hearing aids on the speech and language development of children with hearing loss. JAMA Otolaryngology-Head \& Neck Surgery, 140, 403-409.

Turan, Z., Taşkıran Küçüköncü, D., Cankuvvet, N. \& Yolal, Y. (2012). Koklear implant ve işitme cihazı kullanan işitme kayıplı çocukların dil ve dinleme becerilerinin değerlendirilmesi. Gülhane Tip Dergisi; 54, 142-150. 
Tüfekçioğlu, U. (2010). Speech characteristics of hearing impaired Turkish children. İçinde S. Topbaş ve M. Yavaş (Ed.), Communication disorders in Turkish (s.160-185). Ontario: Multilingual Matters.

Türkmen, A. V., Yiğit, Ö., Akkaya, E., Uğur, E., Kefeciler, Z. \& Gözütok, S. (2013). İstanbul Eğitim ve Araştırma Hastanesi yenidoğan işitme taraması sonuçlarımız, İstanbul Medical Journal;14, 175-80.

Walker, E. A., Spratford, M., Moeller, M., Oleson, J., Ou, H., Roush, P. \& Jacobs, S. (2013). Predictors of hearing aid use time in children with mild-to-severe hearing loss. Language, Speech and Hearing Services in School, 44, 73-88.

Vohr, B. (2003). Overview: Infants and children with hearing loss - part I. Mental Retardation and Developmental Disabilities Research Reviews, 9, 62-64.

Yazgan, H., Keleş, E., Gebeşçi, A., Demirdöven, M. \& Uzun, L. (2012). Yenidoğan işitme taramasında dört yıllık sonuçlarımız, Van Tip Dergisi;19(3), 112-115.

Yoshinaga-Itano, C. (2003). From screening to early identification and intervention: Discovering predictors to successful outcomes for children with significant hearing loss. Journal of Deaf Studies and Deaf Education, 8, 11-30.

Yost, W. (2006). Fundamentals of hearing: An introduction (10.bs.). Arizona: Brill.

Zaidman-Zait, A. \& Most, T. (2005). Cochlear implants in children with hearing loss: Maternal expectations and impact on the family. The Volta Review, 150(2), 129-150. 